\title{
Cerebral autoregulation and neurovascular coupling are progressively impaired during septic shock: an experimental study
}

\author{
Lorenzo Ferlini $^{1 *}\left(\mathbb{D}\right.$, Fuhong Su², Jacques Creteur ${ }^{2}$, Fabio Silvio Taccone ${ }^{2}$ and Nicolas Gaspard ${ }^{1}$
}

\author{
*Correspondence: Iorenzo.ferlini@ \\ erasme.ulb.ac.be \\ ${ }^{1}$ Department of Neurology, Erasme \\ Hospital, Université Libre de \\ Bruxelles, Route de Lennik 808, \\ 1070 Bruxelles, Belgium \\ Full list of author information is \\ available at the end of the article
}

\begin{abstract}
Background: Alteration of the mechanisms of cerebral blood flow (CBF) regulation might contribute to the pathophysiology of sepsis-associated encephalopathy (SAE). However, previous clinical studies on dynamic cerebral autoregulation (dCA) in sepsis had several cofounders. Furthermore, little is known on the potential impairment of neurovascular coupling (NVC) in sepsis. The aim of our study was to determine the presence and time course of dCA and NVC alterations in a clinically relevant animal model and their potential impact on the development of SAE.
\end{abstract}

Methods: Thirty-six anesthetized, mechanically ventilated female sheep were randomized to sham procedures (sham, $n=15)$, sepsis $(n=14)$, or septic shock $(n=7)$. Blood pressure, $\mathrm{CBF}$, and electrocorticography were continuously recorded. Pearson's correlation coefficient Lxa and transfer function analysis were used to estimate dCA. NVC was assessed by the analysis of CBF variations induced by cortical gamma activity (EY) peaks and by the magnitude-squared coherence (MSC) between the spontaneous fluctuations of CBF and EY. Cortical function was estimated by the alpha-delta ratio. Wilcoxon signed rank and rank sum tests, Friedman tests, and RMANOVA test were used as appropriate.

Results: Sepsis and sham animals did not differ neither in dCA nor in NVC parameters. A significant impairment of dCA occurred only after septic shock ( $L x a, p=0.03$, TFA gain $p=$ 0.03 , phase $p=0.01$ ). Similarly, NVC was altered during septic shock, as indicated by a lower MSC in the frequency band $0.03-0.06 \mathrm{~Hz}(p<0.001)$. dCA and NVC impairments were associated with cortical dysfunction (reduction in the alpha-delta ratio $(p=0.03)$ ).

Conclusions: A progressive loss of dCA and NVC occurs during septic shock and is associated with cortical dysfunction. These findings indicate that the alteration of mechanisms controlling cortical perfusion plays a late role in the pathophysiology of SAE and suggest that alterations of CBF regulation mechanisms in less severe phases of sepsis reported in clinical studies might be due to patients' comorbidities or other confounders. Furthermore, a mean arterial pressure targeting therapy aiming to optimize dCA might not be sufficient to prevent neuronal dysfunction in sepsis since it would not improve NVC.

Keywords: Sepsis, Septic shock, Sepsis-associated encephalopathy, Cerebrovascular microcirculation, Neurovascular coupling, Brain dysfunction 


\section{Introduction}

Sepsis-associated encephalopathy (SAE) is defined as cerebral dysfunction that accompanies sepsis in the absence of direct central nervous system infection, structural abnormality, or other causes of encephalopathy [1]. Although mostly reversible, SAE is associated with higher short-term mortality [2] and long-term cognitive impairment among survivors [3]. While its physiopathology is not completely understood [1], in addition to a BBB dysfunction [4-6], several studies suggested alterations of cerebral blood flow (CBF) regulation mechanisms as key factors for SAE [7-11]. Post-mortem studies found widespread ischemic lesions in the brain in septic patients, supporting the role of inadequate cerebral perfusion in SAE [12, 13].

Since brain tissue has a high metabolic demand without efficacious system of substrate storage, CBF is strictly controlled to ensure adequate energy supply [14]. $\mathrm{CBF}$ is determined by cerebral perfusion pressure (CPP, i.e., the differential between the mean arterial pressure (MAP) and the intracranial pressure), cardiac output, and the vascular tone of the small cerebral vessels [15]. In response to variations of CPP, an adaptation of vascular resistance allows CBF to remain stable, a mechanism known as cerebral autoregulation (CA) [16]. It was originally found that $\mathrm{CBF}$ remains constant over a wide range of CPP changes (static cerebral autoregulation, sCA) [16]. Later studies showed that, in that range of CPP values, cerebrovascular autoregulatory capacity depended on the direction (increase vs. decrease) and the speed of changes in CPP [17, 18]. The quantification of fast modifications in cerebrovascular resistance, and consequently in $\mathrm{CBF}$, in relation to rapid changes in MAP within the range of sCA is referred to as "dynamic CA" (dCA). Clinical studies have found alteration of CA in sepsis, especially in the presence of SAE, but they had several confounders: use of vasopressors, variable $\mathrm{CO}_{2}$ arterial pressure $\left(\mathrm{PaCO}_{2}\right)$ or temperature, history of hypertension, age, or the presence of extra-cerebral organ dysfunction $[8,9,19,20]$. Moreover, previous studies included patients with different diseases severity (sepsis and septic shock [21]) evaluated at a variable interval after sepsis diagnosis (between 24 to $72 \mathrm{~h}$ ) and using different methods (time $[8,9,20]$ vs. frequency domain [19]). It is thus still unclear to which extent $\mathrm{CA}$ is altered by sepsis itself and which is the temporal course of its disruption.

CBF is also regulated by neuronal activity. This neurovascular coupling (NVC) is responsible for the fine regulation of oxygen and glucose delivery in response to increase in neuronal activity [22]. Whereas previous studies assessed NVC in stimuli-induced conditions both in septic patients and animal models [22, 23], little is known about NVC during spontaneous cerebral activity, which represents most of cerebral activity in mechanically ventilated sedated patients and lends itself more easily to monitoring. Similarly to CA, important confounders, such as age and extra-cerebral organ dysfunction, were not completely accounted for in these studies [22].

The primary aim of this study was thus to determine the time course of alterations of CA and NVC in a clinically relevant animal sepsis model. Our secondary aim was to determine the presence and time course of the associated cortical dysfunction. 


\section{Materials and methods}

\section{General procedure}

The Institutional Review Board for Animal Care of the Free University of Brussels (Belgium) approved all experimental procedures (number of Ethical Committee approval: $675 \mathrm{~N}$ ), which were also in compliance with ARRIVE (Animal Research: Reporting in Vivo Experiments) guidelines. Care and handling of the animals were in accord with National Institutes of Health guidelines (Institute of Laboratory Animal Resources). The protocol was performed on forty female Ovis Aries sheep. We initially planned to allocate animals with a $1: 1: 1$ ratio in the septic $(n=16)$, septic shock $(n=16)$, or sham groups $(n=16)$. For ethical reasons, in order to limit the number of animals, interim analyses were carried out. This allowed reducing the number of animals in the septic shock group to 8. Sample sizes were based on previous studies from our laboratory using the same animal model [7, 24]. After randomization, animals were excluded if they presented a hemoglobin level below $8 \mathrm{~g} / \mathrm{dl}$ or systemic signs of infection at the moment of the delivery to the laboratory. The general procedures have been described previously [7]; a detailed version is available as Additional Content. Briefly, sheep were mechanically ventilated under general anesthesia provided by continuous IV infusion of ketamine, morphine, and midazolam. Initial doses (ketamine $20 \mathrm{mg} \mathrm{kg}^{-1} \mathrm{~h}^{-1}$; morphine $2 \mathrm{mg} \mathrm{kg}^{-1}$ $\mathrm{h}^{-1}$; midazolam $3 \mathrm{mg} \mathrm{kg}^{-1} \mathrm{~h}^{-1}$ ) were adjusted according to electrocorticography (ECOG) in order to achieve a nearly continuous background (i.e., the fraction of ECOG spent in suppression [amplitudes $<10 \mu \mathrm{V}$ for $\geq 5 \mathrm{~s}$ ] $<10 \%$ ). Muscular blockade was achieved using $10 \mu \mathrm{g} \cdot \mathrm{kg}^{-1} \cdot \mathrm{h}^{-1}$ of rocuronium.

\section{Surgical procedure}

In the sepsis group animals, a midline laparotomy was performed to allow cecum exposure; cecotomy was realized for feces collection $\left(1.5 \mathrm{~g} \cdot \mathrm{kg}^{-1}\right.$ of body weight), and after local disinfection with iodine solution, the cecum was closed with a double suture and returned to the abdominal cavity. A 25-cm plastic tube (Beldico SA, Marche-EnFamenne, Belgium) was inserted through the laparotomy incision in the abdominal cavity for successive feces injection and secured to the abdominal wall which was successively sutured in two layers. In the sham group, laparotomy was performed in order to provide a systemic post-surgical inflammatory response similar to the sepsis group while avoiding the risk of infection. The animal was then turned in the prone position for the brain surgical procedure. Bilateral craniotomy was performed using a highspeed drill (Wuhu Ruijin Medical instrument, Wuhu, China), and two $2.5 \mathrm{~cm}^{2}$ bone holes were opened in the frontal-parietal bones, one on each side, using a laminectomy tool (Aesculap-WerkeAG, Tuttlingen, Germany). The dura mater was opened with scissors, and two 4-contact ECOG electrodes (Dixi Medical, Besançon, France), one per hemisphere, were slipped beneath the dura over the cortex surface of the post-central gyrus and taped to the skull. At a distance of $0.5 \mathrm{~cm}$ from the ECOG electrodes, the dura mater was subsequently punctured to insert a laser Doppler flowmetry probe (OxyFlow 4000, Oxford Optronic, UK) for local cerebral blood flow velocity (CBFv) measurement. All catheters were placed under sterile conditions at a depth of $0.5 \mathrm{~cm}$ into the brain parenchyma as close as possible one to each other. 


\section{Monitoring and measurements}

Ventilator parameters were adjusted to maintain $\mathrm{PaO}_{2}$ between 90 and $120 \mathrm{mmHg}$ $\left(12-16 \mathrm{kPa}\right.$ ) and $\mathrm{PaCO}_{2}$ between 30 and $45 \mathrm{mmHg}(4-6 \mathrm{kPa})$ (as hypercapnia negatively influence CA in sepsis [10]), according to repeated blood gas analysis (Cobas b123, Roche diagnostic, Rotkreuz, Switzerland). Cardiac output and systemic and pulmonary arterial pressure were invasively and continuously measured and recorded simultaneously with ECOG and CBFv with a sampling rate of $250 \mathrm{~Hz}$ (Notocord-hem, Instern Company, France). Measurements of mean pulmonary arterial pressure were collected every $1.5 \mathrm{~h}$. Cardiac index (CI) was calculated using standard formulas; the body surface area was estimated from Mitchell's sheep-specific formula [25].

\section{Experimental protocol}

After the surgical procedures, the animal was allowed to stabilize for $1 \mathrm{~h}$. In all groups, plasmalyte solution and 6\% hydroxy-ethyl starch solution (Voluven; Fresenius Kabi, Schelle, Belgium) were titrated to prevent hypovolemia and arterial hypotension.

\section{Sepsis vs. sham groups}

In the sepsis group, feces were injected into the abdominal cavity, and animals were observed until septic shock (SS) occurred, defined as persisting MAP $<65 \mathrm{mmHg}$ and lactate elevation $>2 \mathrm{mmol} / \mathrm{L}$ despite adequate fluid resuscitation [21]; then, animals were sacrificed using IV potassium chloride. From our previous experiences with this model, we saw that after septic shock, the respiratory parameters are difficult to be controlled without a timing vasopressor therapy; since $\mathrm{PaCO}_{2}$ highly influences cerebrovascular resistance and dCA assessment, animals in the sepsis group were sacrificed after septic shock. In the sham group, data were collected for $12.5 \mathrm{~h}$; then, animals were sacrificed using IV potassium chloride. All analyses were performed offline, using built-in functions and custom scripts in Matlab (The MathWorks, Natick, MA, USA). Since the interval to develop septic shock differed between septic animals, data from sepsis and sham animals were subdivided into four equal time epochs. The first $30 \mathrm{~min}$ for each epoch were selected, and they represented the first four time points $\left(\mathrm{T} 1_{\text {sepsis }}-\mathrm{T} 4_{\text {sepsis }}\right)$; the fifth time point ( $\mathrm{T} 5_{\text {sepsis }}$ ) corresponds to the last $30 \mathrm{~min}$ of the whole recording. The same set of analysis was performed for each time point in all animals.

\section{Septic shock group}

In the septic shock (SS) group, after the initial stabilization period, feces were injected in the abdominal cavity as in the sepsis group. When the response to fluids resuscitation became insufficient, noradrenaline (NA) was started (initial dose $0.5 \mu \mathrm{g} / \mathrm{kg} / \mathrm{min}$ ) and adjusted to maintain MAP around $80 \mathrm{mmHg}$. The response to fluid challenge (250 cc infused in $10 \mathrm{~min}$ ) was deemed insufficient when it resulted in a rise in the $\mathrm{CO}$ inferior to $15 \%$ of the pre-challenge value [26]. The infusion of NA was maintained and titrated up until the MAP did no longer respond to increase in NA dose and fell below $65 \mathrm{mmHg}$. Data during NA infusion were subdivided into four time epochs, and four time points $\left(\mathrm{T} 1_{\mathrm{SS}}-\mathrm{T} 4_{\mathrm{SS}}\right)$ were identified by selecting the first $30 \mathrm{~min}$ for each epoch; in addition, two 30-min time epochs were selected, one immediately before the onset of the NA infusion $\left(\mathrm{T}_{\mathrm{SS}}\right)$ and the second immediately after NA withdrawal $\left(\mathrm{T}_{\mathrm{SS}}\right)$. Since 
the end of the recording in the sepsis group slightly differed from the beginning of NA infusion in the septic shock animals, data collected before $\mathrm{T}_{\mathrm{SS}}$ were discarded for purpose of rigor.

\section{Data analysis}

Data pre-processing

Physiologically implausible values (MAP > $250 \mathrm{mmHg}$ or $<0 \mathrm{mmHg}$; CBFv $>5000$ blood perfusion units (BPU) or $<100 \mathrm{BPU}$; $\mathrm{CO}>15 \mathrm{~L} / \mathrm{min}$ or $<0 \mathrm{~L} / \mathrm{min}$ ) and artifacts were visually removed, prior to further analysis.

\section{Dynamic cerebral autoregulation (dCA)}

$\mathrm{CBFv}$ signals from the 2 hemispheres were averaged, yielding a mean-CBFv (mCBF). For dCA assessment, 2 linear methods, one in the time domain (Lxa) and the other in the time-frequency domain (transfer function analysis, TFA), were employed using recorded spontaneous fluctuations of MAP and mCBF.

For Lxa, MAP and mCBF were further averaged on $10 \mathrm{~s}$ consecutive windows without overlap; then, a Pearson's correlation coefficient between 30 samples of the averaged values was calculated. Lxa can take any value between -1 and 1 . Values close to 1 indicate linear correlation between variables and thus poor autoregulation whereas values closer to 0 , or negative, indicate good autoregulation [27]. In contrast to the previously published Lx index $[28,29]$, obtained with CPP instead of MAP, Lxa index has never been validated in animal or human studies; as a consequence, no cutoff values are available to define autoregulatory failure. On the other hand, a close association was found between the two laser-flow-Doppler derived methods, Lx and Lxa, and it has been previously shown in our model [7] that CPP variations are superimposable to MAP ones since intracranial pressure do not present notable changes.

We used TFA (Matlab TFA function provided by the Cerebral Autoregulation Research Network [30]) to estimate the gain and the phase shift in the very low frequency range (VLF, $0.02<\mathrm{Hz}<0.07$ ), where dCA is supposed to be more efficient [31, 32]. Parameters for TFA were window length of $102.4 \mathrm{~s}$, with $59.9 \%$ overlap and a Hanning window that led to 41 windows and a spectral resolution of $0.009 \mathrm{~Hz}$. Also, each window contained at least one full period oscillation of the lower frequency considered $(0.02 \mathrm{~Hz})$.

\section{Neurovascular coupling}

The methodological steps are summarized in Fig. 1. CBFv from both hemispheres was filtered using a low-pass zero-phase fourth-order Butterworth filter with a cutoff frequency of $0.25 \mathrm{~Hz}$ to limit the higher frequency hemodynamics fluctuations (i.e., due to breathing) [33]. The envelope of the high gamma frequency band (EY), a measure of neuronal cortical activity driving NV C[34], was extracted from the ECOG signal using wavelet transform spectral density estimate ( $c w t$, icwt, and envelope functions in Matlab). Neurovascular coupling was subsequently measured using two different approaches. First, NVC driven by spikes of cortical activity was assessed. Briefly, EY envelope peaks which exceeded one standard deviation above the mean [35] were detected (findpeaks function in Matlab). For each detected EY 


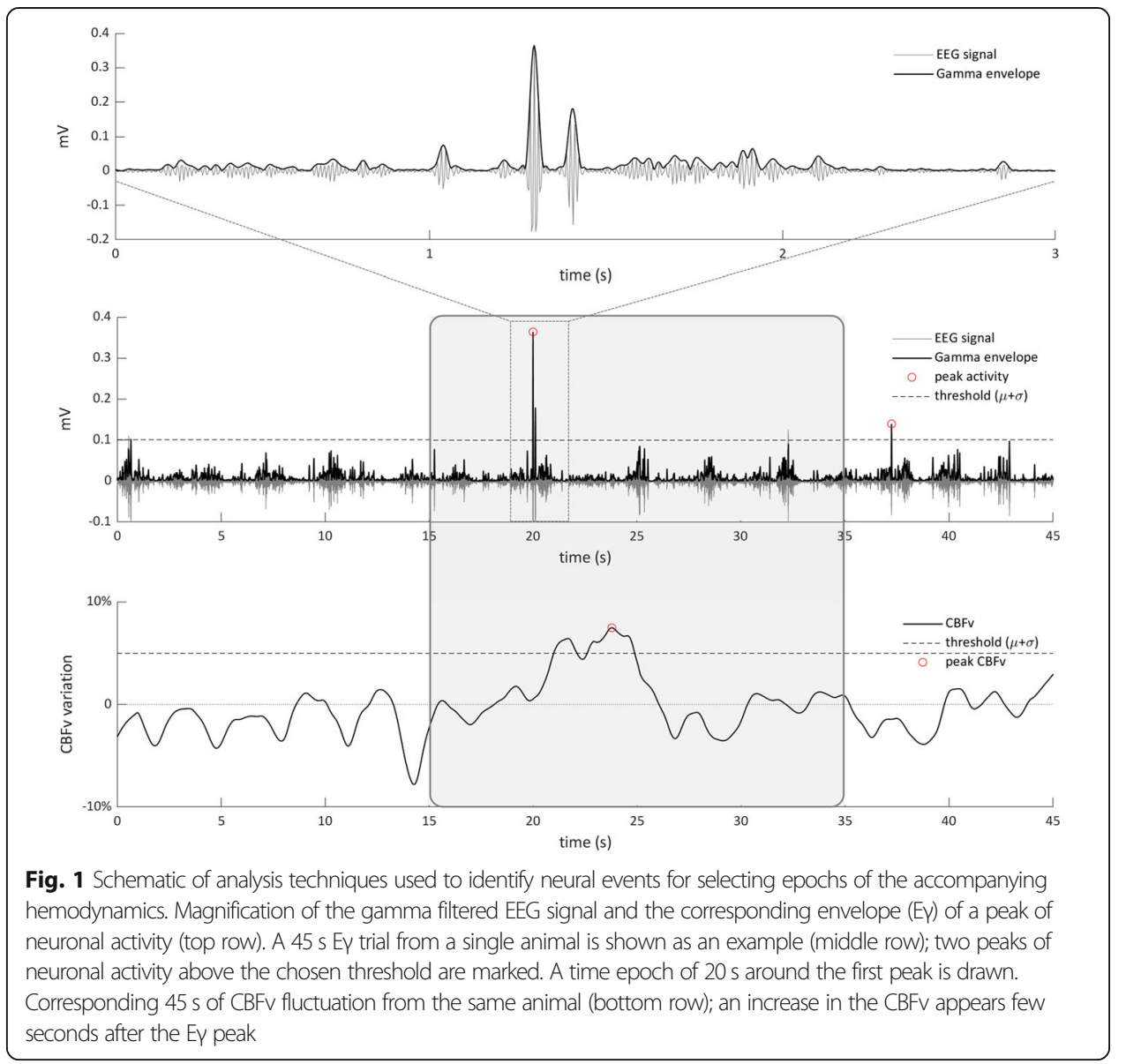

activity peak, $\mathrm{CBFv}$ epochs spanning from $5 \mathrm{~s}$ before to $15 \mathrm{~s}$ after the peak were selected, detrended (detrend function in Matlab), and normalized using the mean and standard deviation calculated on the $5 \mathrm{~s}$ pre-E $\gamma$ peak epoch. If a CBFv peak was identified following the EY peak (findpeaks function in Matlab), the CBF epoch was included for further analysis. For each included CBFv peak, the normalized amplitude and lag from the corresponding $\mathrm{E} \gamma$ peak were calculated. We also assessed the spontaneous fluctuations of $\mathrm{E}_{\gamma}$ (second-level spectrogram) and $\mathrm{CBFv}$ with Welch's periodogram, with an epoch length of $30 \mathrm{~min}$, a window length $180 \mathrm{~s}$, and a window overlap 90\%. Previous studies reported that the main peaks of the alpha and theta EEG second-level spectrum were located between 0.01 and 0.02 $\mathrm{Hz}$, between 0.05 and $0.07 \mathrm{~Hz}$, and between 0.1 and $0.25 \mathrm{~Hz}$ [36-38]. Since gamma band oscillates with a similar periodicity [39], these frequency bands were used for ECOG second-level spectrum analysis. For CBFv fluctuations, the following frequency subcomponents where used, according to the literature: from 0.02 to 0.04 and from 0.04 to $0.15[40,41]$. The coherence between $E_{\gamma}$ signal and the filtered, detrended and normalized CBFv was then measured by MSC, using the same parameters as for the second-level periodogram. Since the literature does not provide any, we identified peaks in the MSC spectrum of early sham animals (Supplemental Figure S1) and identified their frequency boundaries $(0.03$ to $0.06 \mathrm{~Hz}$ and 0.06 to $0.13 \mathrm{~Hz}$ ) and used them for further analysis. 


\section{Alpha-delta ratio}

For each time point described above, ECOG spectrograms were calculated using the Welch's method. The alpha-delta ratio (ADR) was further calculated, as the ratio between power in the alpha $(4-8 \mathrm{~Hz})$ and delta $(0.5-4 \mathrm{~Hz})$ frequency bands.

\section{Statistical analyses}

Statistical analyses were performed using Matlab (The MathWorks, Natick, MA, USA). A $p$ value $<0.05$ was considered statistically significant. The sepsis group was compared to the sham group. In the septic shock group, each animal served as its own control; analyses were performed between time points during NA infusion. While NA is known to affect dCA, this effect is lost in case of sepsis [42]. Consequently, it would have been misleading to compare septic animals under NA infusion with sham animals without vasopressors. This also allowed reducing the number of animals.

The Kolmogorov-Smirnov test was performed to assess the normal distribution of values. Data are presented as median and interquartile range (IQR) or median and median absolute deviation. Wilcoxon signed rank test and Friedman test were used to analyze variable differences in time within single groups, Wilcoxon rank sum test, and two-way repeated-measure ANOVA for differences between groups, as appropriate; the linear step-up procedure introduced by Benjamini and Hochberg was applied for controlling the false discovery rate [43]. Tukey-Kramer and Holm post-hoc analysis were employed in case of a corrected $p$ value $<0.05$.

Since a low MSC could be the result of a noisy signal [44], a cut-off value is necessary to avoid unreliable estimations of gain and phase using the TFA method [45]. The MSC thresholds for a specific frequency were calculated using a Monte Carlo simulation (95\% confidence interval based on 100 repetitions of MSC estimation of randomly values adopting standardized parameters recommended in [45] and specified before). In case of non-significant coherence, corresponding gain and phase values were excluded from analysis. Similarly, the coherence between $\mathrm{E} \gamma$ and CBFv in the assessment of NVC was considered statistically significant if its value for a specific frequency was greater than $95 \%$ confidence limit calculated by a Monte Carlo simulation.

\section{Results}

Thirty-six female sheep were included in the protocol (weight, $25 \mathrm{~kg}$ [interquartile range (IQR) 22-31]); 4 animals were excluded ( $\mathrm{Hb}<8 \mathrm{~g} / \mathrm{dl}, n=1$ in the septic shock group; systemic signs of infection, $n=3$, two in the sepsis group and one in the sham group). In sepsis animals $(n=14)$, SS occurred after a median interval of $12.5 \mathrm{~h}$ [IQR, $10-13.4 \mathrm{~h}]$; in the sham group $(n=15)$, data were collected for $12.5 \mathrm{~h}$. In septic shock group $(n=7)$, the median interval from the beginning of the experiment to the NA infusion was $14.9 \mathrm{~h}$ [IQR, 12-15.1 h]; data were collected for a median of $33.5 \mathrm{~h}$ [IQR, 29.7-33.8 h], until spontaneous death occurred.

\section{Systemic parameters}

Evolution of systemic hemodynamics, respiratory, and biological variables over time in the sepsis and the sham animals are presented in Table 1. A significant increase in 


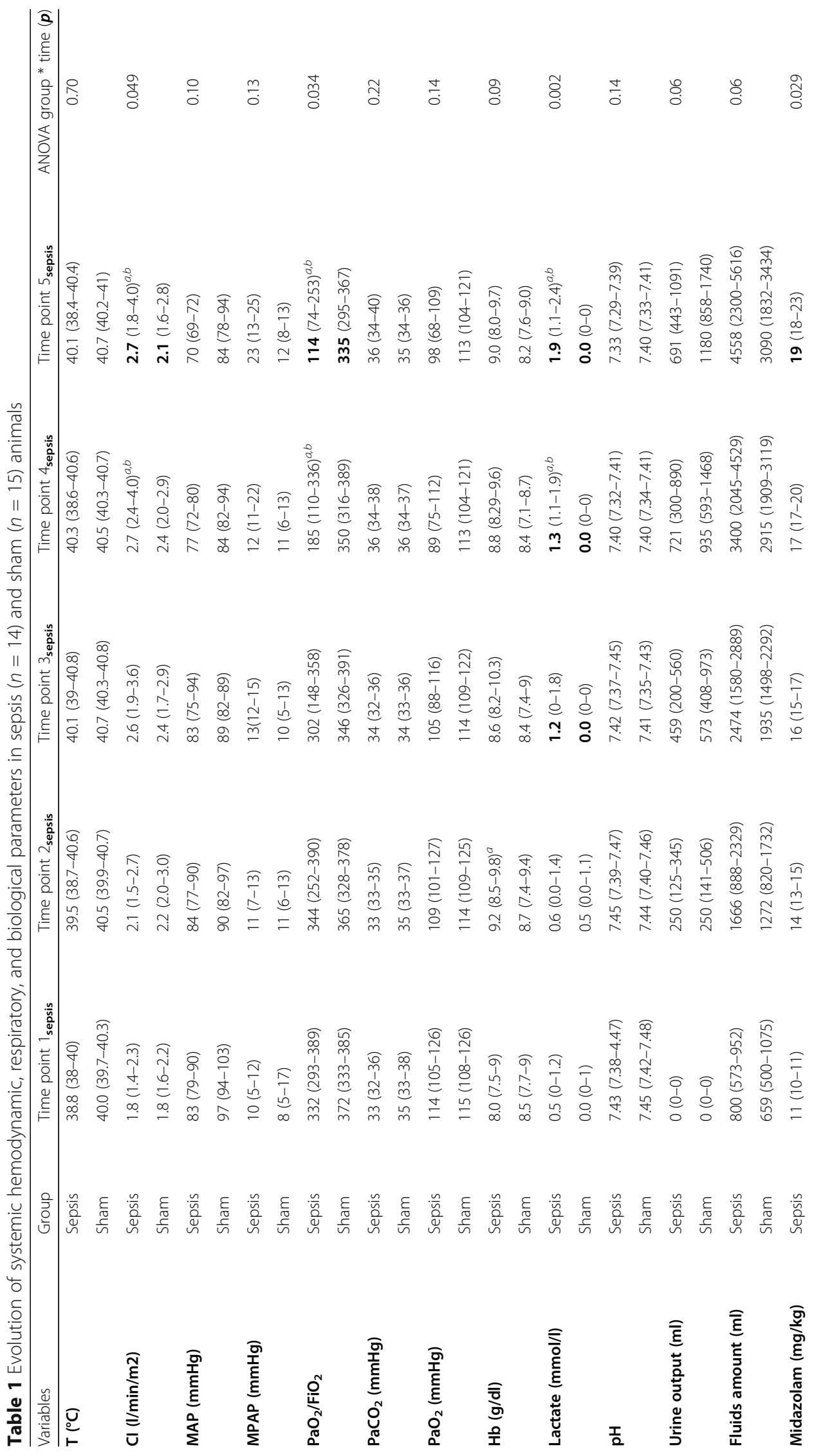




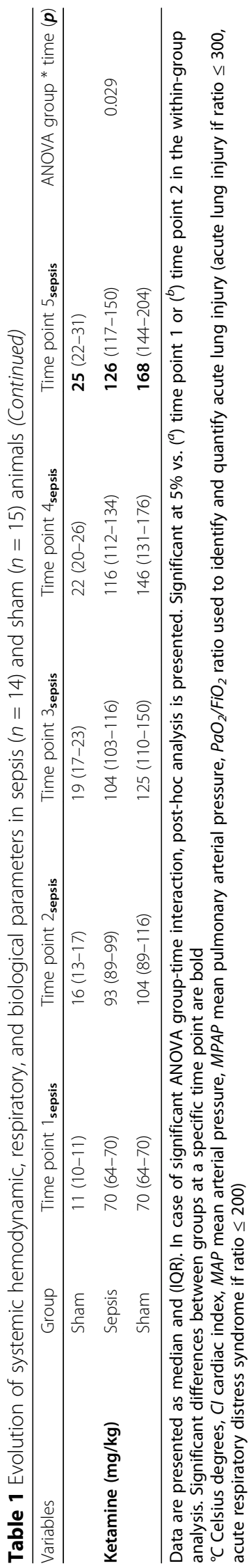


cardiac index marked the onset of the hyperdynamic state of sepsis and was associated with increase in lactatemia and reduction in the $\mathrm{Pa} / \mathrm{FiO}$ ratio.

Table 2 shows the evolution of the same systemic parameters during the septic shock phase. NA infusion allowed to maintain a value of MAP around $80 \mathrm{mmHg}$ (median 78 mmHg; IQR, 74.5-80.4); NA total doses were similar between animals $(5.1 \pm 0.3 \mathrm{mg} /$ kg). $\mathrm{PaCO}_{2}$ and $\mathrm{PaO}_{2}$ did not vary significantly throughout the experiment. A slight and non-significant increase in $\mathrm{PaCO}_{2}$ was observed in the late time points $\left(\mathrm{T}_{4 \mathrm{SS}}\right)$ in the septic shock animals (Table 2). Nevertheless, no animal had $\mathrm{PaCO}_{2}$ values outside the normal range.

\section{Cerebral autoregulation}

Changes in the dCA parameters at different time points are summarized in Fig. 2. We found no difference in the Lxa or in the TFA parameters between the sepsis and sham groups. In the septic shock animals, the Lxa significantly increased between $\mathrm{T} 1_{\mathrm{SS}}$ and T4 $4_{\text {SS. }}$ Upon NA withdrawal, Lxa approached unity, indicating complete loss of dCA. Both TFA parameters showed comparable trends towards a late reduction in the efficacy of dCA in the septic shock group, approximately $5 \pm 1.8 \mathrm{~h}$ before Lxa. We found no significant correlations between dCA parameters (TFA and Lxa, $p=0.19$ and $p=$ 0.46 , respectively) and $\mathrm{PaCO}_{2}(p=0.27)$.

\section{Neurovascular coupling}

We found no significant difference in the percentage of $\mathrm{E} \gamma$ peaks followed by $\mathrm{CBFv}$ peaks, the amplitude and lag of the CBFv peaks, between or within the sham and sepsis groups, although there was a trend towards a decrease in EY peaks followed by $\mathrm{CBFv}$ peaks in the last time point in the sepsis group (Supplemental Figure S2). Similarly, none of the parameter showed a significant change during septic shock, although there was again a decreasing trend in the percentage of $\mathrm{E}_{\gamma}$ peaks followed by $\mathrm{CBFv}$ peaks with progressing sepsis. The second-level $\mathrm{E} \gamma$ spectrum, the periodogram of $\mathrm{CBFv}$, and the MSC between $E_{\gamma}$ and CBF did not show any significant change in the sham and sepsis groups (Supplemental Figure S3a (A,C), S3b (A,C,E), S3c (A,C)). However, we observed a significant decrease between $\mathrm{T} 1_{\mathrm{SS}}$ (immediately after $\mathrm{NA}$ ) and $\mathrm{T} 4_{\mathrm{SS}}$ (last time point prior to cessation of NA) in spontaneous fluctuations of CBFv in frequencies between 0.04 and 0.15 , as well as in MSC between $\mathrm{E}_{\gamma}$ and CBFv in frequencies between 0.03 and $0.06 \mathrm{~Hz}$ (Fig. 3).

\section{Cortical activity}

Finally, as shown in Fig. 4, the alpha/delta ratio of the ECOG signal remained stable during sepsis but showed a significant decrease during septic shock.

\section{Discussion}

We formally demonstrate, in a clinically relevant animal model, that $\mathrm{dCA}, \mathrm{NVC}$, and cortical functions are impaired at the time of septic shock, supporting the hypothesis that SAE is, at least in part, a consequence of relative cerebral hypoperfusion.

Animal studies prior to this one concluded that CA was not altered in sepsis but only measured static CA (sCA) [46-48], a finding that was in line with human studies [11, 


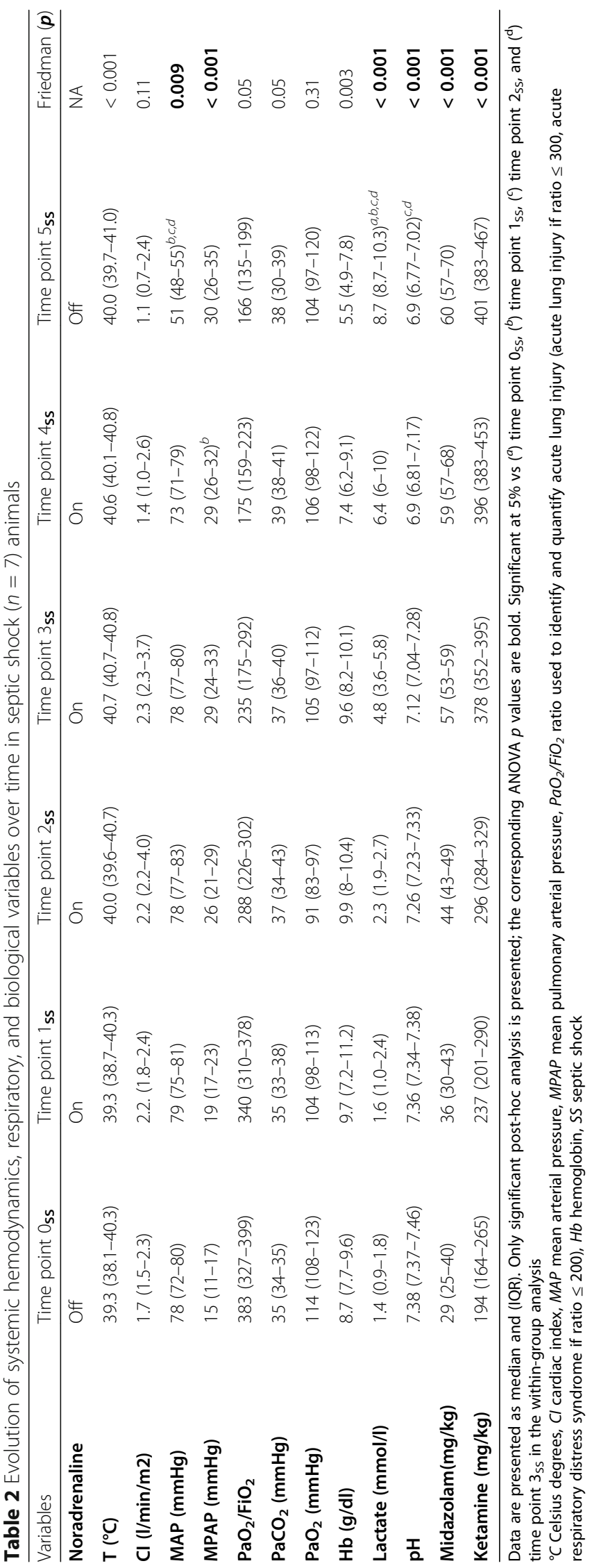




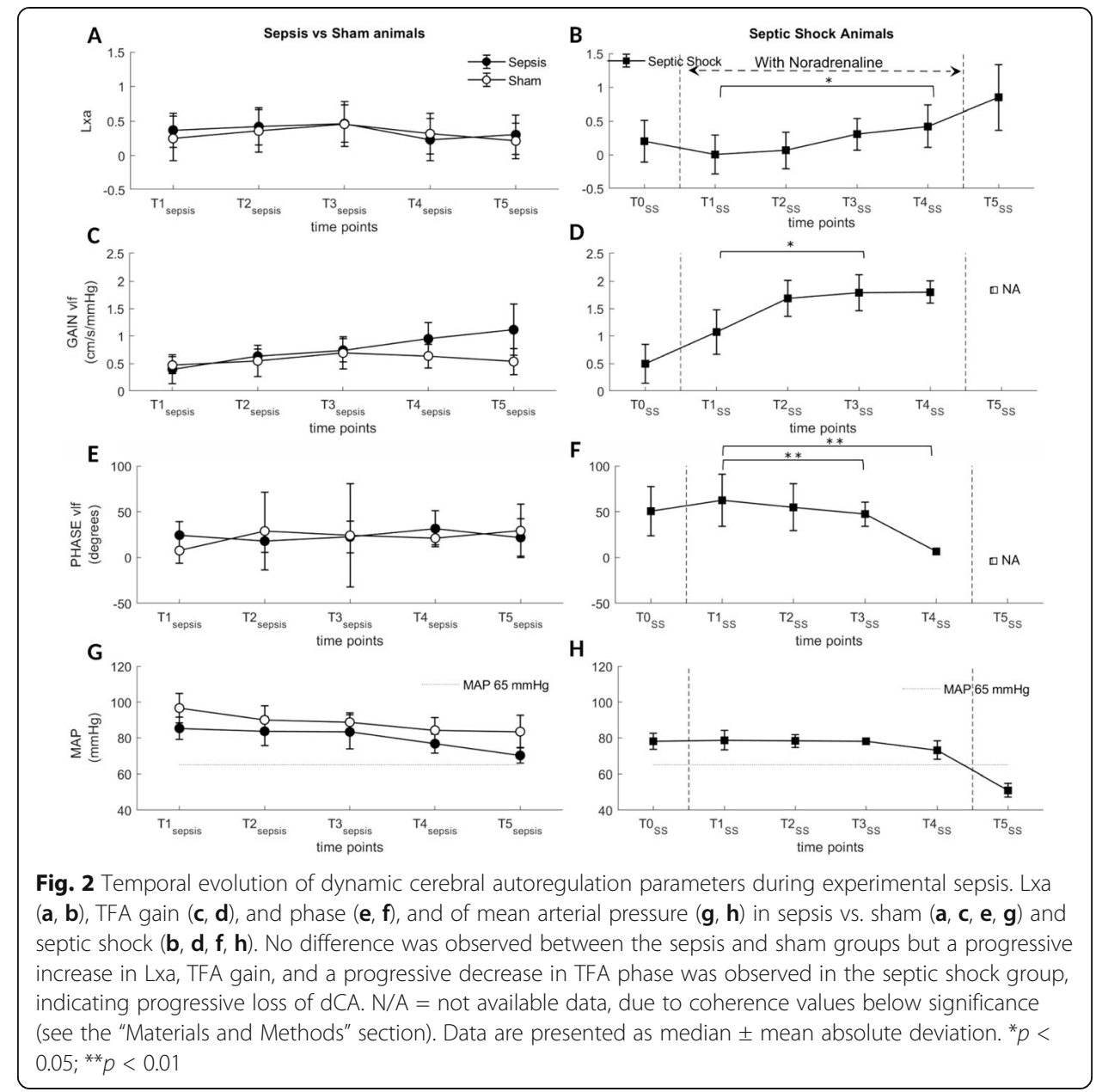

19, 49]. Our findings are thus more in line with clinical studies that suggested that $\mathrm{dCA}$ is altered during sepsis $[8,9,19,20]$, particularly $[8,9]$ or exclusively $[20]$ in patients with SAE. Of note, a dissociation of sCA and $\mathrm{dCA}$ has been also observed in other clinical settings, such in anesthetized or in stroke patients [50, 51]. Our model also minimizes chronic and acute confounders that were unavoidable in human studies and allows us to conclude that mechanisms of dCA are impaired per se at the time of septic shock. The longitudinal analysis indicates that $\mathrm{dCA}$ impairment is a dynamic process, as suggested by prior experiments with LPS infusion [19, 52, 53]. Both timedomain (Lxa) and frequency-domain (TFA) metrics yielded similar results, but TFA showed changes earlier than Lxa. Although experimental studies have shown a poor sensitivity of gain alone as indicator of autoregulatory performance, the concomitant reduction in the phase shift, associated with a significant coherence, makes this finding more reliable [54]. Nevertheless, no previous studies have compared Lxa and TFA performance in describing variations in autoregulation, and this question is beyond the scope of this work. We thus cannot draw any firm conclusion on the comparative sensitivity and specificity of both approaches.

As seemingly opposed to some human studies, however, the alteration in $\mathrm{dCA}$ occurred only after the onset of septic shock in our model. Again, we made this observation at controlled normal MAP levels in otherwise healthy animals, which strongly 

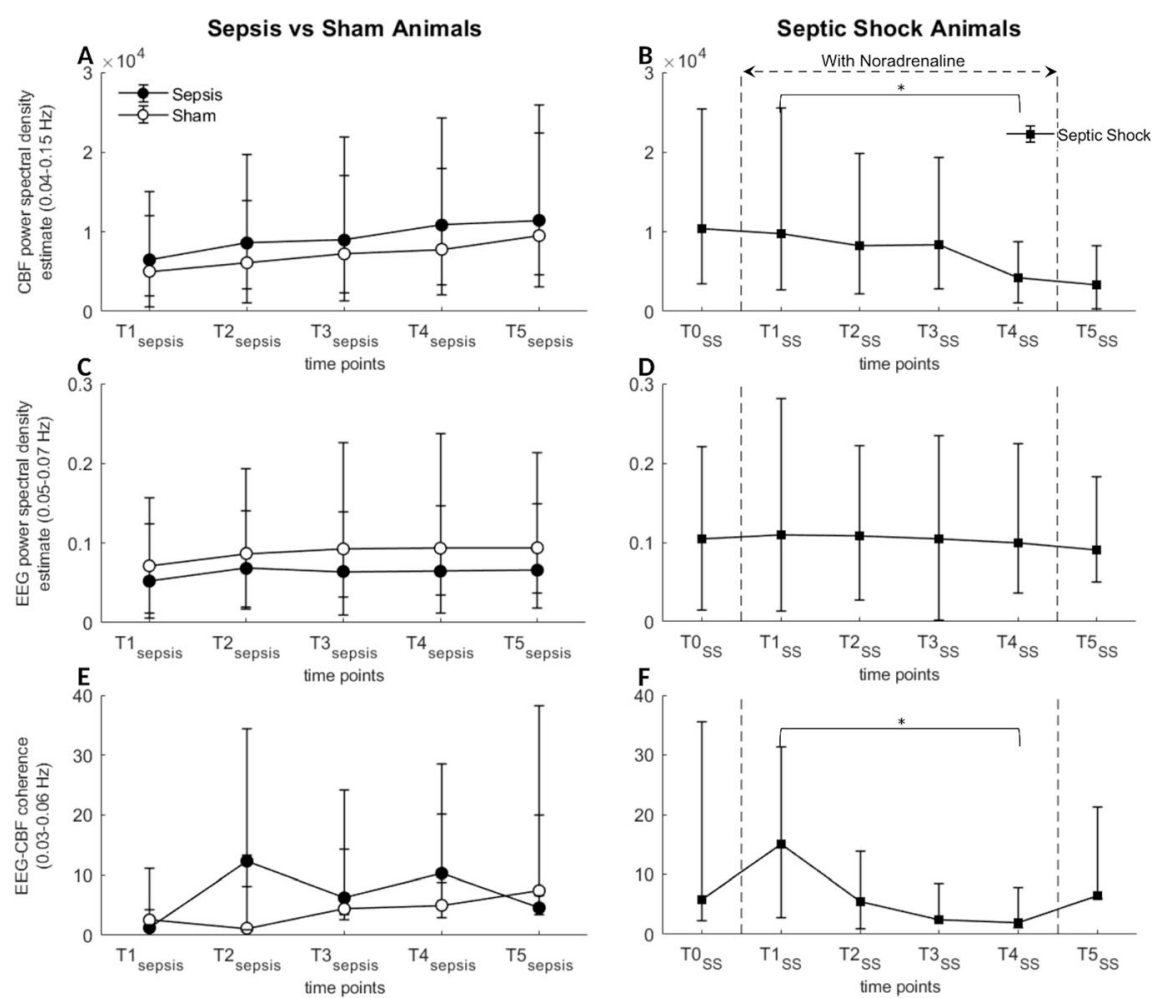

Fig. 3 Temporal evolution of neurovascular coupling measured by coherence between periodic fluctuations of cortical activity and cerebral blood flow. Cerebral blood flow velocity (CBFv) spectral power $(0.04-0.15 \mathrm{~Hz}$ frequency band; $\mathbf{a}, \mathbf{b}$ ), second-level spectral power of gamma activity envelope (EY; $0.05-0.07 \mathrm{~Hz}$ frequency band; $\mathbf{c}, \mathbf{d}$ ), and their magnitude-squared coherence (MSC; $0.03-0.06 \mathrm{~Hz}$ frequency band; $\mathbf{e}$, $\mathbf{f}$ ) in sepsis vs. sham groups $(\mathbf{a}, \mathbf{c}, \mathbf{e})$ and in septic shock group $(\mathbf{b}, \mathbf{d}, \mathbf{f})$, expressed as median and inter-quartile range. ${ }^{*} p<0.05$ by RMANOVA test analysis. No significant difference, neither in CBFv nor in Ey spectra fluctuations nor in MSC, was observed in sepsis and sham animals in any of the frequency bands considered. In the septic shock group, there was a significant decrease between $\mathrm{T}_{\mathrm{ss}}$ and $\mathrm{T} 4_{\mathrm{ss}}$ in the spectrum of $\mathrm{CBFv}$ fluctuations between 0.04 and $0.15 \mathrm{~Hz}$ and a significant decrease in MSC for frequencies between 0.03 and $0.06 \mathrm{~Hz}$. Comparative analysis for other frequencies of CBFv and EY spectral power and MSC are presented in Supplemental Figure S3 $(a, b, c)$. Power spectral density estimation are expressed in $\sqrt{ } \mathrm{dB} / \mathrm{Hz}$

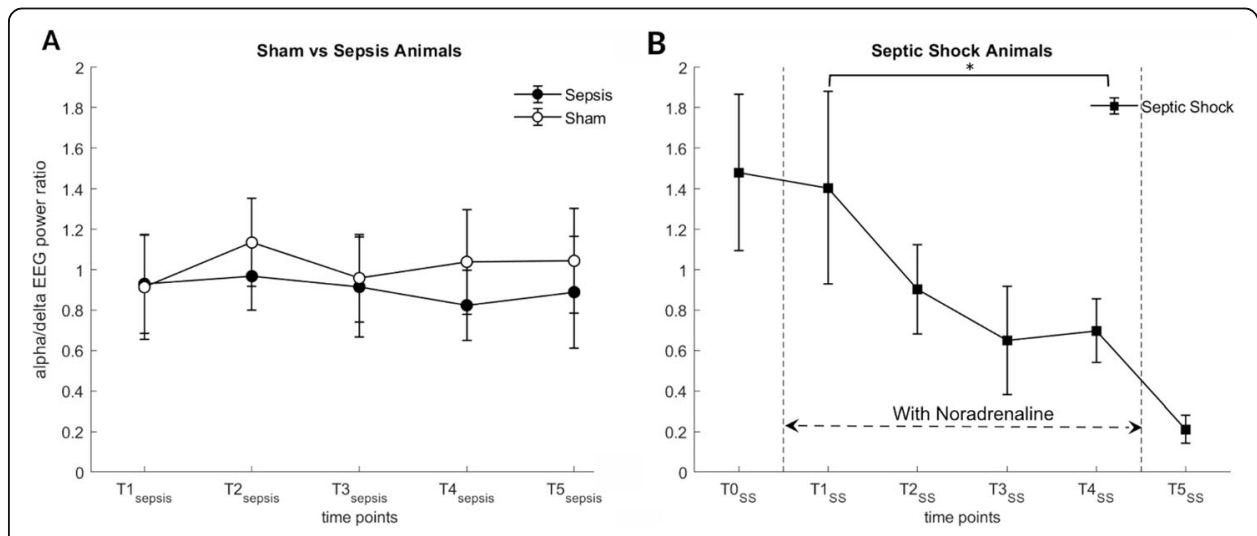

Fig. 4 Temporal evolution of cortical activity during experimental sepsis. Alpha/delta ratio of the ECOG signal in sepsis vs. sham (a) and septic shock (b) group. No difference is observed in the sepsis and sham groups. There is a significant decrease in ADR in the septic shock group between $T 1_{S S}$ and $T 4_{\text {ss. }}$. Data are presented as median \pm mean absolute deviation; ${ }^{*} p<0.05$ 
indicates an intrinsic alteration of dCA. Although we did not formally demonstrate it, this acute alteration probably indicates a narrowing of the plateau of the autoregulatory curve, rather than a shift in the overall curve [55]. On the other hand, clinical studies have shown that the ranges of the plateau of the autoregulatory curve are highly variable between individuals [56,57], with elderly patients and those with a chronic hypertension demonstrating a right shift of the curve, i.e., elevated lower limit of the plateau $[58,59]$. As age and pre-existing cerebrovascular disorders are also well-known risk factors of SAE [60-62], it is thus possible that the alteration of CA in the less severe phases of sepsis observed in some studies $[9,20,63]$ is due to a level of MAP below the lower limit of a right-shifted autoregulatory curve, rather than an alteration of CA per se. Of note, although LPS infusion does not fully recapitulate the pathophysiology of sepsis, an experimental study in healthy volunteers receiving LPS, which mimics the early phase of sepsis, did not demonstrate an alteration of CA [64]. It is also possible that patients with chronic cerebrovascular disorder might show earlier sensitivity to sepsis-induced alterations in dCA.

Whereas earlier studies assessed NVC in stimuli-induced conditions both in septic patients and animals models [22, 23], little is known about NVC during spontaneous brain activity. In contrast to these studies, which found a reduction in amplitude [22] and a delay [23] in the $\mathrm{CBFv}$ response to stimulus-induced cortical activity, we found no significant variations in the amplitude or in the time lag of the CBFv response, independently from the EEG frequency band assessed, even if a trend in the reduction of the CBFv response was observed when comparing the percentage of EEG peaks followed by a CBFv peak. These differences with previous studies could be due to the fact that the magnitude of spontaneous variations in cortical activity is not sufficient to challenge CBF regulation. However, an alteration in the coherence between cortical activity and $\mathrm{CBFv}$ was observed during septic shock, indicating a reduced efficiency of cerebral vessels to adjust CBF to spontaneous fluctuations of cortical activity.

Finally, alterations in cortical activity, as assessed by the ADR, also became evident at the time $\mathrm{dCA}$ and NVC were altered, after the onset of shock, and despite a MAP maintained within a normal range. This temporal sequence thus suggests that the pathophysiological mechanisms of CA and NVC impairment might be similar to those leading to systemic circulatory failure, such as general microvascular dysfunction [19]. These findings also indicate that the intrinsic alterations in the mechanisms of CBF homeostasis are indeed causing part of the cortical dysfunction associated with sepsis. Most studies on carbon dioxide-induced cerebral vasoreactivity in sepsis also confirm cerebral microcirculation failure $[10,65]$. Other animal studies showed structural microcirculation changes induced by sepsis, such as the reduction in the proportion of cortical perfused vessels [7] probably attributable to endothelial adhesion of leucocytes and platelet [66], astrocyte end-feet [5], and pericytes [67] detachment from the vessel walls, and increased blood-brain barrier (BBB) permeability $[4,68]$ contributing to altered extracellular milieu of the brain and to disrupt the neurovascular unit. Previous studies suggested a prominent role of BBB dysfunction, mediated by cytokines such as TNF- $\alpha$ in SAE $[4,6,69]$. In humans, severe encephalopathy assessed by EEG was associated with higher CSF protein level of protein, suggestive of an increase in BBB permeability [70]. These structural changes at the endothelial and blood-brain barrier levels may be partly responsible for the functional cerebrovascular dysfunction we described. 
Furthermore, endothelin-1 contributes to CBF impairment by stimulating brain inflammation in sepsis [71]. Endothelin receptors antagonist have shown some promising results on microcirculation and mitochondrial dysfunction in sepsis [72, 73], and their effect on dCA and NVC could be further studied in our model.

Our study provides some leads for future clinical applications and studies. First, with the limitations discussed above, our results suggest that it could be possible to replace stimulus-induced assessment of NVC by analysis of the coherence of spontaneous fluctuation of CBF and neuronal activity. Since NVC reflects a physiologically complemental aspect of CBF regulation, it should be assessed as frequently as cerebral autoregulation, but the lack of standardized and automated protocol of analysis for critically ill patients limits the utility of stimulus-induced NVC assessment in clinical practice [74]. Further studies in humans are, therefore, necessary to evaluate feasibility and efficacy of non-stimulus-induced NVC assessment. Second, the observation that not only CA but also NCV is impaired during septic shock also raises the possibility that strategies aiming at optimizing MAP or even CA might not fully prevent the brain from injuries caused by loss of NVC. Structural changes potentially responsible for the neurovascular unit disruption, as discussed above, are not reversed by optimization of CPP. Further research should focus on strategies preventing or reversing neurovascular unit disruption (for example, reducing oxidative stress [74]) in order to preserve NVC function. Again, it would be required to assess NVC in the ICU. Finally, the integration of $\mathrm{dCA}$ and NVC concepts into prognostic and therapeutic approaches would improve the clinical application of these tools. This may guide future randomized trials in choosing the right therapeutic intervention (optimal target MAP therapies in patients with $\mathrm{dCA}$ alteration only and coupled therapies in those presenting NVC impairment too) in order to show if focusing on cerebral circulation improves care of septic patients, as it seemed to be the case in preliminary studies in other conditions $[75,76]$.

Our study presents some limitations. The laser Doppler technique has been widely employed to measure regional changes in $\mathrm{CBF}$ thanks to its high temporal resolution $[23,77]$. However, this technique presents several limitations, not least the fact that it measures velocity rather than flow, it overestimate high increase in CBF in comparison with some reference methods [78], and absolute values are extremely heterogenous [79]; for this reason, results have to be interpreted cautiously. We followed some procedures to circumvent these limitations. The probe was secured in its initial position in order to prevent artifacts. Moreover, for each animal and for each time point, $\mathrm{CBFv}$ data were normalized and averaged across the two hemispheres, before calculation of Lx and TFA, both measures reflecting the relation between CBF and MAP fluctuations rather than absolute values. Second, it is well known that the pressure-flow relationship is nonlinear $[31,55]$ because of the variation in vascular resistance as a consequence of changes in MAP and the effect of other parameters, such as $\mathrm{PaCO}_{2}$, that might influence CBF. Since the complexity of most nonlinear methods precludes the physiological interpretation of the results [55], linear models are usually employed, and a lack of linearity between MAP and CBF in these models is interpreted as a normal CA [45]. A lack of linearity could also be the result of a low signal-to-noise ratio leading to a misinterpretation of data. In order to circumvent this issue, we estimated minimal meaningful coherence thresholds and excluded gain and phase unreliable results. Thus, our results should be robust and reliable. Moreover, there were no significant correlations 
between dCA parameters and $\mathrm{PaCO}_{2}$, ruling out the possibility that $\mathrm{PaCO}_{2}$ variations could have confounded dCA estimations. Third, previous studies examined the influence of sedation on $\mathrm{dCA}$, showing that it is enhanced by midazolam and probably also by ketamine $[80,81]$, both of which were used in these experiments. However, although we cannot rule out the possibility that absolute dCA values might have been influenced by sedation, especially ketamine, we found no statistically significant differences between the sepsis and sham groups. Further, prolonged experiments, associated with an increasing cumulative amount of sedative drugs, disclosed a decrease in dCA. The effect of sedation on NVC at the moment is unclear. Fourth, high doses of NA can affect dCA [42]. A study in healthy volunteers has suggested that NA effect on cerebral vasculature might be partially due to increase in ventilation via a $\beta$-adrenergic stimulation of the carotid chemoreceptors [42]. Since animals were mechanically ventilated, NA could not influence ventilation frequency. So, as septic shock animals served as their own control and NA-induced $\mathrm{PaCO}_{2}$ variations were controlled by mechanical ventilation, the NA influence on CA assessment was probably limited. Finally, in order to limit for potential confounders, we did not employ specific sepsis therapies, such as antibiotics, since it has been shown that they can modify BBB [82], influence central nervous system inflammation [83, 84], and induce seizures [85]; on the other hand, this do not allow an entire translation of our results to clinical practice. Furthermore, albeit sheep is a promising surrogate for modelling human brain diseases [86], interspecies differences limit the generalization of animals studies results to humans.

\section{Conclusions}

In this clinically relevant model of sepsis, we observed a progressive loss of $\mathrm{dCA}$ and NVC, in septic shock, and this was associated with cortical neuronal dysfunction. These findings indicate that the alteration of mechanisms controlling cortical perfusion plays a role in the pathophysiology of SAE; both dCA and NVC should be assessed in clinical practice and therapies targeting only CA could not be efficacious to prevent neuronal dysfunction. NVC assessment without stimulation protocols could increase the employment of this tool in clinical practice. Further study should aim to clarify the molecular mechanisms of dCA and NVC alterations and to develop prognostic and therapeutic approaches as well.

\section{Supplementary information}

Supplementary information accompanies this paper at https://doi.org/10.1186/s40635-020-00332-0.

Additional file 1. This section contains five additional figures and a word file with detailed Materials and Methods section and figure legends. Supplemental figure S1 provides a representation of power spectra of magnitudesquared coherence in sham group used in the neurovascular coupling analysis process, while supplemental figure S2 and S3 $(a, b, c)$ provide additional results pertaining to neurovascular coupling analysis.

\footnotetext{
Abbreviations

ADR: Alpha-delta ratio; BBB: Blood-brain barrier; BPU: Blood perfusion unit; CA: Cerebral autoregulation; sCA: Static cerebral autoregulation; dCA: Dynamic cerebral autoregulation; CBF: Cerebral blood flow; mCBF: Mean cerebral blood flow; CBFv: Cerebral blood flow velocity; Cl: Cardiac index; CO: Cardiac output; CPP: Cerebral perfusion pressure; ECOG: Electrocorticography; EEG: Electroencephalogram; EY: Envelope of the cortical high gamma activity; HR: Heart rate; IQR: Interquartile range; MAP: Mean arterial pressure; MPAP: Mean pulmonary arterial pressure; MSC: Magnitudesquared coherence; NA: Noradrenaline; NVC: Neurovascular coupling; $\mathrm{PaCO}_{2}$ : Arterial carbon dioxide partial pressure; $\mathrm{PaO}_{2}$ : Arterial oxygen partial pressure; PEEP: Positive end-expiratory pressure; SAE: Sepsis-associated encephalopathy; SS: Septic shock; TFA: Transfer function analysis; VLF: Very low frequencies
} 


\section{Acknowledgements}

Not applicable.

\section{Authors' contributions}

N.G., F.S.T., and J.C. conceived the original idea and designed the model. L.F. and F.S. carried out the experiments. L.F. collected the data, performed the analytic calculations and interpretation, and wrote the manuscript directly supervised by N.G. All authors discussed the results, commented on the manuscript, and approved the final version to be published.

\section{Funding}

This work was supported by the Fonds Erasme pour la Recherche Médicale-Convention de Recherche d'Excellence and the Fonds National pour la Recherche Scientifique.

\section{Availability of data and materials}

The datasets used and/or analyzed during the current study are available from the corresponding author on reasonable request.

\section{Ethics approval and consent to participate}

The Institutional Review Board for Animal Care of the Free University of Brussels (Belgium) approved all experimental procedures, which were also in compliance with ARRIVE (Animal Research: Reporting in Vivo Experiments) guidelines. Care and handling of the animals were in accord with National Institutes of Health guidelines (Institute of Laboratory Animal Resources).

\section{Consent for publication}

Not applicable.

\section{Competing interests}

The authors declare that they have no competing interests.

\section{Author details}

'Department of Neurology, Erasme Hospital, Université Libre de Bruxelles, Route de Lennik 808, 1070 Bruxelles, Belgium. ${ }^{2}$ Department of Intensive Care, Erasme Hospital, Université Libre de Bruxelles, Bruxelles, Belgium.

Received: 4 June 2020 Accepted: 21 July 2020

\section{Published online: 14 August 2020}

\section{References}

1. Gofton TE, Young GB (2012) Sepsis-associated encephalopathy. Nat Rev Neurol 8:557-566. https://doi.org/10.1038/ nrneurol.2012.183

2. Sprung CL, Peduzzi PN, Shatney CH, Schein RH, Wilson MF, Sheagren JN, Hinshaw LB (1990) Impact of encephalopathy on mortality in the sepsis syndrome. Crit Care Med 18:801-806

3. Iwashyna TJ, Ely EW, Smith DM, Langa KM (2010) Long-term cognitive impairment and functional disability among survivors of severe sepsis. JAMA 304:1787. https://doi.org/10.1001/jama.2010.1553

4. du Moulin GC, Paterson D, Hedley-Whyte J, Broitman SA (1985) E. coli peritonitis and bacteremia cause increased bloodbrain barrier permeability. Brain Res 340:261-268

5. Papadopoulos MC, Lamb FJ, Moss RF, Davies DC, Tighe D (1979) Bennett ED (1999) Faecal peritonitis causes oedema and neuronal injury in pig cerebral cortex. Clin Sci Lond Engl 96:461-466

6. Alexander JJ, Jacob A, Cunningham P, Hensley L, Quigg RJ (2008) TNF is a key mediator of septic encephalopathy acting through its receptor, TNF receptor-1. Neurochem Int 52:447-456. https://doi.org/10.1016/j.neuint.2007.08.006

7. Taccone FS, Su F, Pierrakos C, He X, James S, Dewitte O, Vincent J-L, Backer DD (2010) Cerebral microcirculation is impaired during sepsis: an experimental study. Crit Care 14:1-10. https://doi.org/10.1186/cc9205

8. Schramm P, Klein K, Falkenberg L, Berres M, Closhen D, Werhahn KJ, David M, Werner C, Engelhard K (2012) Impaired cerebrovascular autoregulation in patients with severe sepsis and sepsis-associated delirium. Crit Care 16:R181. https://doi.org/10.1186/cc11665

9. Crippa IA, Subirà C, Vincent J-L, Fernandez RF, Hernandez SC, Cavicchi FZ, Creteur J, Taccone FS (2018) Impaired cerebral autoregulation is associated with brain dysfunction in patients with sepsis. Crit Care 22:327. https://doi.org/10 1186/s13054-018-2258-8

10. Taccone FS, Castanares-Zapatero D, Peres-Bota D, Vincent J-L, Berre' J, Melot C (2010) Cerebral autoregulation is influenced by carbon dioxide levels in patients with septic shock. Neurocrit Care 12:35-42 . https://doi.org/10.1007/ s12028-009-9289-6

11. Matta BF, Stow PJ (1996) Sepsis-induced vasoparalysis does not involve the cerebral vasculature: indirect evidence from autoregulation and carbon dioxide reactivity studies. Br J Anaesth 76:790-794

12. Sharshar T, Annane D, de la Grandmaison GL, Brouland JP, Hopkinson NS, Françoise G (2004) The neuropathology of septic shock. Brain Pathol Zurich Switz 14:21-33

13. Heming N, Mazeraud A, Verdonk F, Bozza FA, Chrétien F, Sharshar T (2017) Neuroanatomy of sepsis-associated encephalopathy. Crit Care 21:65. https://doi.org/10.1186/s13054-017-1643-z

14. Brown AM, Ransom BR (2007) Astrocyte glycogen and brain energy metabolism. Glia 55:1263-1271. https://doi.org/10. 1002/glia.20557

15. Willie CK, Tzeng Y, Fisher JA, Ainslie PN (2014) Integrative regulation of human brain blood flow. J Physiol 592:841-859 https://doi.org/10.1113/jphysiol.2013.268953

16. LASSEN NA (1959) Cerebral blood flow and oxygen consumption in man. Physiol Rev 39:183-238 
17. Birch AA, Dirnhuber MJ, Hartley-Davies R, lannotti F, Neil-Dwyer G (1995) Assessment of autoregulation by means of periodic changes in blood pressure. Stroke 26:834-837

18. Schmidt B, Klingelhöfer J, Perkes I, Czosnyka M (2009) Cerebral autoregulatory response depends on the direction of change in perfusion pressure. J Neurotrauma 26:651-656. https://doi.org/10.1089/neu.2008.0784

19. Berg RMG, Plovsing RR, Ronit A, Bailey DM, Holstein-Rathlou N-H, Møller K (2012) Disassociation of static and dynamic cerebral autoregulatory performance in healthy volunteers after lipopolysaccharide infusion and in patients with sepsis. Am J Physiol-Regul Integr Comp Physiol 303:R1127-R1135. https://doi.org/10.1152/ajpregu.00242.2012

20. Pfister D, Siegemund M, Dell-Kuster S, Smielewski P, Rüegg S, Strebel SP, Marsch SC, Pargger H, Steiner LA (2008) Cerebral perfusion in sepsis-associated delirium. Crit Care 12:1-9. https://doi.org/10.1186/cc6891

21. Singer M, Deutschman CS, Seymour CW, Shankar-Hari M, Annane D, Bauer M, Bellomo R, Bernard GR, Chiche J-D, Coopersmith CM, Hotchkiss RS, Levy MM, Marshall JC, Martin GS, Opal SM, Rubenfeld GD, van der Poll T, Vincent J-L, Angus DC (2016) The third international consensus definitions for sepsis and septic shock (Sepsis-3). JAMA 315:801. https://doi.org/10.1001/jama.2016.0287

22. Rosengarten B, Krekel D, Kuhnert S, Schulz R (2012) Early neurovascular uncoupling in the brain during community acquired pneumonia. Crit Care 16:1-8. https://doi.org/10.1186/cc11310

23. Rosengarten B, Hecht M, Auch D, Ghofrani HA, Schermuly RT, Grimminger F, Kaps M (2006) Microcirculatory dysfunction in the brain precedes changes in evoked potentials in endotoxin-induced sepsis syndrome in rats. Cerebrovasc Dis 23: 140-147. https://doi.org/10.1159/000097051

24. Taccone FS, Su F, Deyne CD, Abdellhai A, Pierrakos C, He X, Donadello K, Dewitte O, Vincent J-L, Backer DD (2014) Sepsis is associated with altered cerebral microcirculation and tissue hypoxia in experimental peritonitis*. Crit Care Med 42:e114. https://doi.org/10.1097/ccm.0b013e3182a641b8

25. Berman A (2003) Effects of body surface area estimates on predicted energy requirements and heat stress. J Dairy Sci 86:3605-3610 . https://doi.org/10.3168/jds.50022-0302(03)73966-6

26. Cecconi M, De Backer D, Antonelli M, Beale R, Bakker J, Hofer C, Jaeschke R, Mebazaa A, Pinsky MR, Teboul JL, Vincent $J \mathrm{~L}$, Rhodes A (2014) Consensus on circulatory shock and hemodynamic monitoring. Task force of the European Society of Intensive Care Medicine. Intensive Care Med 40:1795-1815. https://doi.org/10.1007/s00134-014-3525-z

27. Zeiler FA, Donnelly J, Cardim D, Menon DK, Smielewski P, Czosnyka M (2018) ICP versus laser Doppler cerebrovascular reactivity indices to assess brain autoregulatory capacity. Neurocrit Care 28:194-202. https://doi.org/10.1007/s12028-017-0472-x

28. Brady KM, Lee JK, Kibler KK, Smielewski P, Czosnyka M, Easley RB, Koehler RC, Shaffner DH (2007) Continuous timedomain analysis of cerebrovascular autoregulation using near-infrared spectroscopy. Stroke 38:2818-2825. https://doi. org/10.1161/STROKEAHA.107.485706

29. Lam JM, Hsiang JN, Poon WS (1997) Monitoring of autoregulation using laser Doppler flowmetry in patients with head injury. J Neurosurg 86:438-445. https://doi.org/10.3171/jns.1997.86.3.0438

30. Cerebral Autoregulation Research Network.http://www.car-net.org/content/resources. Accessed 2 June 20.

31. Zhang R, Zuckerman JH, Giller CA, Levine BD (1998) Transfer function analysis of dynamic cerebral autoregulation in humans. Am J Physiol 274:H233-H241. https://doi.org/10.1152/ajpheart.1998.274.1.H233

32. Panerai RB (2007) Cerebral autoregulation: from models to clinical applications. Cardiovasc Eng 8:42-59. https://doi.org/ $10.1007 /$ s10558-007-9044-6

33. Saka (2010) Linear superposition of sensory-evoked and ongoing cortical hemodynamics. Front Neuroenergetics. https://doi.org/10.3389/fnene.2010.00023

34. Bergel A, Deffieux T, Demené C, Tanter M, Cohen I (2018) Local hippocampal fast gamma rhythms precede brain-wide hyperemic patterns during spontaneous rodent REM sleep. Nat Commun 9:5364. https://doi.org/10.1038/s41467-018-07752-3

35. Bruyns-Haylett M, Harris S, Boorman L, Zheng Y, Berwick J, Jones M (2013) The resting-state neurovascular coupling relationship: rapid changes in spontaneous neural activity in the somatosensory cortex are associated with haemodynamic fluctuations that resemble stimulus-evoked haemodynamics. Eur J Neurosci 38:2902-2916. https://doi. org/10.1111/ejn.12295

36. Novak P (1992) Lepicovska V. Slow modulation of EEG: NeuroReport 3:189-192. https://doi.org/10.1097/00001756-199202000-00017

37. Novak P, Lepicovska V, Dostalek C (1992) Periodic amplitude modulation of EEG. Neurosci Lett 136:213-215 . https://doi. org/10.1016/0304-3940(92)90051-8

38. Admiraal MM, Gilmore EJ, Van Putten MJAM, Zaveri HP, Hirsch LJ (2017) Gaspard N. Disruption of brain-heart coupling in sepsis: J Clin Neurophysiol 34:413-420. https://doi.org/10.1097/WNP.0000000000000381

39. Colgin LL, Denninger T, Fyhn M, Hafting T, Bonnevie T, Jensen O, Moser M-B, Moser El (2009) Frequency of gamma oscillations routes flow of information in the hippocampus. Nature 462:353-357. https://doi.org/10.1038/nature08573

40. Zhang Z, Khatami R (2014) Predominant endothelial vasomotor activity during human sleep: a near-infrared spectroscopy study. Eur J Neurosci 40:3396-3404. https://doi.org/10.1111/ejn.12702

41. Bosch BM, Bringard A, Ferretti G, Schwartz S, Iglói K (2017) Effect of cerebral vasomotion during physical exercise on associative memory, a near-infrared spectroscopy study. Neurophotonics 4:041404. https://doi.org/10.1117/1.NPh.4.4. 041404

42. Berg RM, Plovsing RR, Bailey DM, Holstein-Rathlou N-H, Møller K (2015) The dynamic cerebral autoregulatory adaptive response to noradrenaline is attenuated during systemic inflammation in humans. Clin Exp Pharmacol Physiol 42:740746. https://doi.org/10.1111/1440-1681.12421

43. Benjamini Y, Hochberg Y (1995) Controlling the false discovery rate - a practical and powerful approach to multiple testing. Journal of the Royal Statistical Society Series B: Methodological:289-300. https://doi.org/10.2307/2346101

44. Giller CA (1990) The frequency-dependent behavior of cerebral autoregulation: Neurosurgery 27:362-368. https://doi. org/10.1227/00006123-199009000-00004

45. Claassen JA, Abeelen ASM den, Simpson DM, Panerai RB, (CAet) on behalf of the international CARN (2016) Transfer function analysis of dynamic cerebral autoregulation: a white paper from the International Cerebral Autoregulation Research Network. J Cereb Blood Flow Metab 36:665-680 . https://doi.org/10.1177/0271678×15626425

46. Pedersen M, Brandt CT, Knudsen GM, Østergaard C, Skinhøj P, Skovsted IC, Frimodt-Møller N, Møller K (2008) The effect of S. Pneumoniae bacteremia on cerebral blood flow autoregulation in rats. J Cereb Blood Flow Metab 28:126-134. https://doi.org/10.1038/sj.jcbfm.9600514 
47. Takala J, Booke M, Westphal M, Hinder F, Traber LD, Traber DL (2003) Cerebral blood flow is not altered in sheep with Pseudomonas aeruginosa sepsis treated with norepinephrine or nitric oxide synthase inhibition. Anesth Analg 96:11221128 , table of contents

48. Rosengarten $B$, Hecht M, Wolff S, Kaps M (2008) Autoregulative function in the brain in an endotoxic rat shock model. Inflamm Res 57:542-546. https://doi.org/10.1007/s00011-008-7199-2

49. Smith SM, Padayachee S, Modaresi KB, Smithies MN, Bihari DJ (1998) Cerebral blood flow is proportional to cardiac index in patients with septic shock. J Crit Care 13:104-109 . https://doi.org/10.1016/S08839441(98)90013-2

50. Dawson SL, Blake MJ, Panerai RB, Potter JF (2000) Dynamic but not static cerebral autoregulation is impaired in acute ischaemic stroke. Cerebrovasc Dis 10:126-132. https://doi.org/10.1159/000016041

51. Strebel S, Lam A, Matta B, Mayberg TS, Aaslid R, Newell DW (1995) Dynamic and static cerebral autoregulation during isoflurane, desflurane, and propofol anesthesia: Anesthesiology 83:66-76. https://doi.org/10.1097/00000542-19950700000008

52. Andreasen A, Krabbe K, Krogh-Madsen R, Taudorf S, Pedersen B, Moller K (2008) Human endotoxemia as a model of systemic inflammation. Curr Med Chem 15:1697-1705. https://doi.org/10.2174/092986708784872393

53. Berg RMG, Plovsing RR, Bailey DM, Holstein-Rathlou N-H, Møller K (2016) Dynamic cerebral autoregulation to induced blood pressure changes in human experimental and clinical sepsis. Clin Physiol Funct Imaging 36:490-496. https://doi. org/10.1111/cpf.12256

54. Govindan RB, Brady KM, Massaro AN, Perin J, Jennings JM, DuPlessis AJ, Koehler RC, Lee JK (2018) Comparison of frequency- and time-domain autoregulation and vasoreactivity indices in a piglet model of hypoxia-ischemia and hypothermia. Dev Neurosci 40:547-559. https://doi.org/10.1159/000499425

55. Tan CO (2012) Defining the characteristic relationship between arterial pressure and cerebral flow. J Appl Physiol 113: 1194-1200. https://doi.org/10.1152/japplphysiol.00783.2012

56. Joshi B, Ono M, Brown C, Brady K, Easley RB, Yenokyan G, Gottesman RF (2012) Hogue CW. Predicting the limits of cerebral autoregulation during cardiopulmonary bypass: Anesth Analg 114:503-510. https://doi.org/10.1213/ANE. Ob013e31823d292a

57. Hori D, Brown C, Ono M, Rappold T, Sieber F, Gottschalk A, Neufeld KJ, Gottesman R, Adachi H, Hogue CW (2014) Arterial pressure above the upper cerebral autoregulation limit during cardiopulmonary bypass is associated with postoperative delirium. Br J Anaesth 113:1009-1017. https://doi.org/10.1093/bja/aeu319

58. Aries MJH, Elting JW, De Keyser J, Kremer BPH, Vroomen PCAJ (2010) Cerebral autoregulation in stroke: a review of transcranial Doppler studies. Stroke 41:2697-2704. https://doi.org/10.1161/STROKEAHA.110.594168

59. Gao Y, Zhang M, Han Q, Li W, Xin Q, Wang Y, Li Z (2015) Cerebral autoregulation in response to posture change in elderly subjects-assessment by wavelet phase coherence analysis of cerebral tissue oxyhemoglobin concentrations and arterial blood pressure signals. Behav Brain Res 278:330-336. https://doi.org/10.1016/j.bbr.2014.10.019

60. Eames PJ, Blake MJ, Dawson SL, Panerai RB, Potter JF (2002) Dynamic cerebral autoregulation and beat to beat blood pressure control are impaired in acute ischaemic stroke. J Neurol Neurosurg Psychiatry 72:467-472. https://doi.org/10. 1136/jnnp.72.4.467

61. Sonneville R, de Montmollin E, Poujade J, Garrouste-Orgeas M, Souweine B, Darmon M, Mariotte E, Argaud L, Barbier F, Goldgran-Toledano D, Marcotte G, Dumenil A-S, Jamali S, Lacave G, Ruckly S, Mourvillier B, Timsit J-F (2017) Potentially modifiable factors contributing to sepsis-associated encephalopathy. Intensive Care Med 43:1075-1084. https://doi.org/ 10.1007/s00134-017-4807-z

62. Paulson OB, Strandgaard S, Edvinsson L (1990) Cerebral autoregulation. Cerebrovasc Brain Metab Rev 2:161-192

63. Steiner LA, Pfister D, Strebel SP, Radolovich D, Smielewski P, Czosnyka M (2009) Near-infrared spectroscopy can monitor dynamic cerebral autoregulation in adults. Neurocrit Care 10:122-128. https://doi.org/10.1007/s12028-008-9140-5

64. Berg RM, Plovsing RR, Evans KA, Christiansen CB, Bailey DM, Holstein-Rathlou N-H, Møller K (2013) Lipopolysaccharide infusion enhances dynamic cerebral autoregulation without affecting cerebral oxygen vasoreactivity in healthy volunteers. Crit Care 17:R238. https://doi.org/10.1186/cc13062

65. Terborg C, Schummer W, Albrecht M, Reinhart K, Weiller C, Röther J (2001) Dysfunction of vasomotor reactivity in severe sepsis and septic shock. Intensive Care Med 27:1231-1234

66. Vachharajani V, Russell JM, Scott KL, Conrad S, Stokes KY, Tallam L, Hall J, Granger DN (2010) Obesity exacerbates sepsisinduced inflammation and microvascular dysfunction in mouse brain. Microcirculation 12:183-194. https://doi.org/10. 1080/10739680590904982

67. Nishioku T, Dohgu S, Takata F, Eto T, Ishikawa N, Kodama KB, Nakagawa S, Yamauchi A, Kataoka Y (2009) Detachment of brain pericytes from the basal lamina is involved in disruption of the blood-brain barrier caused by lipopolysaccharideinduced sepsis in mice. Cell Mol Neurobiol 29:309-316. https://doi.org/10.1007/s10571-008-9322-x

68. Sharshar T, Hopkinson NS, Orlikowski D, Annane D (2004) The brain in sepsis - culprit and victim. Crit Care 9:37. https:// doi.org/10.1186/cc2951

69. Papadopoulos MC, Davies DC, Moss RF, Tighe D (2000) Bennett ED. Pathophysiology of septic encephalopathy: a review: Crit Care Med 28:3019-3024. https://doi.org/10.1097/00003246-200008000-00057

70. Young GB, Bolton CF, Archibald YM, Austin TW (1992) Wells GA. The electroencephalogram in sepsis-associated encephalopathy: J Clin Neurophysiol 9:145-152. https://doi.org/10.1097/00004691-199201000-00016

71. van Gool WA, van de Beek D, Eikelenboom P (2010) Systemic infection and delirium: when cytokines and acetylcholine collide. The Lancet 375:773-775 . https://doi.org/10.1016/S0140-6736(09)61158-2

72. Rutai A, Fejes R, Juhász L, Tallósy SP, Poles MZ, Földesi I, Mészáros AT, Szabó A, Boros M, Kaszaki J (2019) Endothelin A and $B$ receptors: potential targets for microcirculatory-mitochondrial therapy in experimental sepsis. SHOCK 1. https:// doi.org/10.1097/SHK.0000000000001414

73. Naito Y, Yoshioka K, Tanaka K, Tatsumi K, Kimura S, Kasuya Y (2014) Endothelin B receptor-mediated encephalopathic events in mouse sepsis model. Life Sci 118:340-346. https://doi.org/10.1016/j.lfs.2014.03.012

74. Phillips AA, Chan FH, Zheng M, Krassioukov AV, Ainslie PN (2015) Neurovascular coupling in humans: physiology, methodological advances and clinical implications. J Cereb Blood Flow Metab 0271678X15617954. https://doi.org/10. 1177/0271678x15617954 
75. Ono M, Arnaoutakis GJ, Fine DM, Brady K, Easley RB, Zheng Y, Brown C, Katz NM, Grams ME, Hogue CW (2013) Blood pressure excursions below the cerebral autoregulation threshold during cardiac surgery are associated with acute kidney injury*: Crit Care Med 41:464-471. https://doi.org/10.1097/CCM.0b013e31826ab3a1

76. Aries MJH, Czosnyka M, Budohoski KP, Steiner LA, Lavinio A, Kolias AG, Hutchinson PJ, Brady KM, Menon DK, Pickard JD, Smielewski P (2012) Continuous determination of optimal cerebral perfusion pressure in traumatic brain injury*: Crit Care Med 40:2456-2463. https://doi.org/10.1097/CCM.0b013e3182514eb6

77. Florence G, Seylaz J (1992) Rapid autoregulation of cerebral blood flow: a laser-Doppler flowmetry study. J Cereb Blood Flow Metab 12:674-680. https://doi.org/10.1038/jcbfm.1992.92

78. Fabricius M, Lauritzen M (1996) Laser-Doppler evaluation of rat brain microcirculation: comparison with the [ $\left.{ }^{14} \mathrm{C}\right]$ iodoantipyrine method suggests discordance during cerebral blood flow increases. J Cereb Blood Flow Metab 16:156161. https://doi.org/10.1097/00004647-199601000-00018

79. Dirnagl U, Kaplan B, Jacewicz M, Pulsinelli W (1989) Continuous measurement of cerebral cortical blood flow by laser-Doppler flowmetry in a rat stroke model. J Cereb Blood Flow Metab 9:589-596. https://doi.org/10.1038/jcbfm. 1989.84

80. Ogawa Y, Iwasaki K, Aoki K, Gokan D, Hirose N, Kato J (2010) Ogawa S. The different effects of midazolam and propofol sedation on dynamic cerebral autoregulation: Anesth Analg 111:1279-1284. https://doi.org/10.1213/ANE. 0b013e3181f42fc0

81. Engelhard K, Werner C, Möllenberg O, Kochs E (2001) S(+)-ketamine/propofol maintain dynamic cerebrovascular autoregulation in humans. Can J Anesth Can Anesth 48:1034-1039. https://doi.org/10.1007/BF03016597

82. Wu Q, Zhang Y, Zhang Y, Xia C, Lai Q, Dong Z, Kuang W, Yang C, Su D, Li H, Zhong Z (2020) Potential effects of antibiotic-induced gut microbiome alteration on blood-brain barrier permeability compromise in rhesus monkeys. Ann N Y Acad Sci nyas.14312. https://doi.org/10.1111/nyas.14312

83. Adembri C, Selmi V, Vitali L, Tani A, Margheri M, Loriga B, Carlucci M, Nosi D, Formigli L, De Gaudio AR (2014) Minocycline but not tigecycline is neuroprotective and reduces the neuroinflammatory response induced by the superimposition of sepsis upon traumatic brain injury*: Crit Care Med 42:e570-e582. https://doi.org/10.1097/CCM. 0000000000000414

84. Melzer N, Meuth SG, Torres-Salazar D, Bittner S, Zozulya AL, Weidenfeller C, Kotsiari A, Stangel M, Fahlke C, Wiendl $\mapsto$ (2008) A B-lactam antibiotic dampens excitotoxic inflammatory CNS damage in a mouse model of multiple sclerosis. PLoS ONE 3:e3149. https://doi.org/10.1371/journal.pone.0003149

85. Chow KM, Hui AC, Szeto CC (2005) Neurotoxicity induced by beta-lactam antibiotics: from bench to bedside. Eur J Clin Microbiol Infect Dis 24:649-653. https://doi.org/10.1007/s10096-005-0021-y

86. Kaiser E, West F (2020) Large animal ischemic stroke models: replicating human stroke pathophysiology. Neural Regen Res 15:1377. https://doi.org/10.4103/1673-5374.274324

\section{Publisher's Note}

Springer Nature remains neutral with regard to jurisdictional claims in published maps and institutional affiliations.

\section{Submit your manuscript to a SpringerOpen ${ }^{\circ}$ journal and benefit from:}

- Convenient online submission

- Rigorous peer review

- Open access: articles freely available online

- High visibility within the field

- Retaining the copyright to your article

Submit your next manuscript at $>$ springeropen.com 